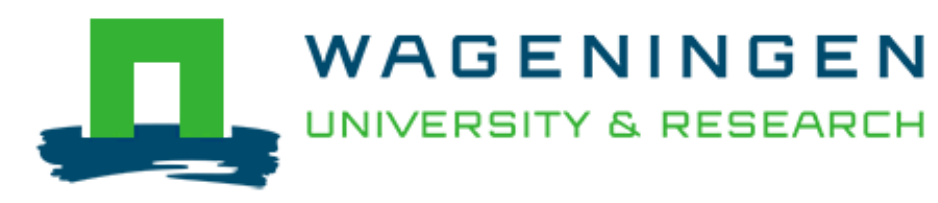

\title{
Effects of loose housing and the provision of alternative nesting material on peri-partum sow behaviour and piglet survival
}

Bolhuis, J. E., Raats-van den Boogaard, A. M. E., Hoofs, A. I. J., \& Soede, N. M.

This is a "Post-Print" accepted manuscript, which has been published in "Applied Animal Behaviour Science"

This version is distributed under a non-commercial no derivatives Creative Commons (c) (1) $\Theta \Theta$ reproduction in any medium, provided the original work is properly cited and not used for commercial purposes. Further, the restriction applies that if you remix, transform, or build upon the material, you may not distribute the modified material.

Please cite this publication as follows:

Bolhuis, J. E., Raats-van den Boogaard, A. M. E., Hoofs, A. I. J., \& Soede, N. M. (2018). Effects of loose housing and the provision of alternative nesting material on peri-partum sow behaviour and piglet survival. Applied Animal Behaviour Science, 202, 28-33. DOI: 10.1016/j.applanim.2018.01.004

You can download the published version at:

https://doi.org/10.1016/j.applanim.2018.01.004 


\section{Accepted Manuscript}

Title: Effects of loose housing and the provision of alternative nesting material on peri-partum sow behaviour and piglet survival

Authors: J.E. Bolhuis, A.M.E. Raats-van den Boogaard, A.I.J. Hoofs, N.M. Soede

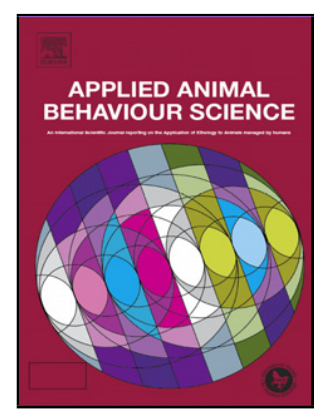

PII:

DOI:

Reference: S0168-1591(18)30009-1

To appear in https://doi.org/10.1016/j.applanim.2018.01.004

To appear in: APPLAN 4583

Received date:

APPLAN

Revised date:

7-9-2017

Accepted date:

Please cite this article as: Bolhuis, J.E., Raats-van den Boogaard, A.M.E., Hoofs, A.I.J., Soede, N.M., Effects of loose housing and the provision of alternative nesting material on peri-partum sow behaviour and piglet survival.Applied Animal Behaviour Science https://doi.org/10.1016/j.applanim.2018.01.004

This is a PDF file of an unedited manuscript that has been accepted for publication. As a service to our customers we are providing this early version of the manuscript. The manuscript will undergo copyediting, typesetting, and review of the resulting proof before it is published in its final form. Please note that during the production process errors may be discovered which could affect the content, and all legal disclaimers that apply to the journal pertain. 
Effects of loose housing and the provision of alternative nesting material on peri-partum sow behaviour and piglet survival

J.E. Bolhuis ${ }^{1}$, A.M.E. Raats-van den Boogaard ${ }^{1}$, A.I.J. Hoofs ${ }^{2}$, N.M. Soede ${ }^{1}$

${ }^{1}$ Adaptation Physiology Group, Department of Animal Sciences, Wageningen University, PO Box 338, $6700 \mathrm{AH}$ Wageningen, The Netherlands

${ }^{2}$ Wageningen Livestock Research

\title{
Highlights
}

- Use of jute sacks and straw balls as nesting material was studied in loose-housed and crated sows

- Effects of nesting material and housing were additive

- Loose housing and the provision of nesting materials reduced activity before parturition

- Loose housing and the provision of nesting materials reduced restlessness during parturition

- Less crushing events tended to occur in loose pens vs crates during parturition

\begin{abstract}
Sows are strongly motivated to perform nestbuilding behaviour before parturition. This behaviour is often restricted in commercial systems due to confinement of the sow and lack of suitable nesting material to be used on slatted floors. This study aimed to investigate effects of loose vs. crated housing and the provision of alternative nesting material on periparturient sow behaviour and piglet survival. In a $2 \times 2$ arrangement, sixty-eight sows were assigned to either
\end{abstract}


loose housing or crates and were either or not provided with nesting material consisting of jute sacks and straw balls. All sows had a rope. Postures and manipulation of materials and pen were observed using 5-min scan sampling for the $12 \mathrm{~h}$ before and the $24 \mathrm{~h}$ after parturition. Behaviour during parturition was scored continuously and included nose-nose contact between sow and piglets and crushing incidences. No interactions between treatments were found. In the $12 \mathrm{~h}$ prepartum, loose housed sows showed less sitting (5 vs. 9\%) and ventral lying (29 vs. 38\%) and more lateral lying (33 vs. 23\%) and floor manipulation (10 vs. 5\%) than crated sows. During parturition, loose housed sows spent less time sitting ( 2 vs. $6 \%$ ), had fewer postural changes (34 vs. 50), showed less fence manipulation (0.1 vs. $2 \%)$ and had more nose contact with piglets (56 vs. 19 times). Provision of nesting material increased pre-partum lying (63 vs. 57\%), increased manipulation of materials (14 vs. $8 \%$ ) and reduced manipulation of floor ( 5 vs. $10 \%$ ) and fence (5 vs. 9\%). During parturition, sows with nesting material showed less standing (6 vs. $10 \%$ ) and more lying (90 vs. $84 \%$ ). No effects were found on behaviour in the $24 \mathrm{~h}$ after parturition or on parturition duration $(3.3 \pm 0.1 \mathrm{~h})$. During parturition, the times lying down and the number of piglets that died by crushing tended to be lower with provision of nesting material (0.1 vs. 0.3). In the $48 \mathrm{~h}$ after parturition, loose housed sows crushed more piglets. In conclusion, both loose housing and the provision of alternative nesting materials affected prepartum sow behaviour and resulted in less activity during parturition, with some tendencies for beneficial effects on (near-) crushing of piglets during this period. In conclusion, both loose housing and the provision of alternative nesting materials, likely particularly the jute sacks, have a beneficial effect on periparturient sow behaviour.

Key words: sow, parturition, loose housing, enrichment, nest-building, behaviour 


\section{Introduction}

Modern sows still have a strong motivation to build a nest before parturition (Gustafsson et al., 1999). From about $24 \mathrm{~h}$ before parturition, nest building starts and becomes more intense between about 12 and $6 \mathrm{~h}$ prepartum (Algers and Uvnäs-Moberg, 2007; Wischner et al., 2009). Expression of nest building behaviour seems to positively affect the parturition process and, on the longer term, post-partum sow behaviour and piglet performance (see Yun and Valros, 2015 for review). In intensive pig husbandry systems, however, most sows are kept in farrowing crates during parturition and lactation, which strongly restricts their movements and the possibility to perform nest building behaviour (Jarvis et al., 2004). Several studies have demonstrated that confinement of sows around parturition may lead to increased stress responses (Jarvis et al., 2002; Lawrence et al., 1994; Oliviero et al., 2008). Compared to sows farrowing loose-housed in a pen, sows kept in crates have been reported to show more posture changes during parturition (Hansen and Curtis, 1980) and a longer duration of parturition (Oliviero et al., 2008), both of which are risk factors of piglet mortality. Apart from being confined around parturition, sows are often not provided with suitable materials for nest building. A lack of these materials leads to less elaborate nest building activities before parturition (Yun et al., 2014). Facilitating nest building behaviour by providing suitable materials and/or space positively affects periparturient maternal behaviour (Andersen et al., 2014; Yun et al., 2014, see also reviews by Wischner et al., 2009; Yun and Valros, 2015). For instance, the provision of nesting materials increased responsiveness of sows to piglet screams (Cronin and Van Amerongen, 1991; app. 75dB, Herskin et al., 1998) and the combination of loose housing and nesting materials increased lateral lying (Oliviero et al., 2008), which increases udder accessibility. 
Most studies on nesting material have used straw (e.g. Burne et al., 2000; Thodberg et al., 1999; Hansen and Curtis, 1980) in various quantities (up to $25 \mathrm{~kg}$, Westin et al., 2015), either or not accompanied by other nesting materials (Yun et al., 2013). Many pig farmers, are, however, reluctant to use straw as it may fall through the slatted floors and block the slurry system (reviewed by Tuyttens, 2005). The aim of this study, therefore, was to study effects of alternative nesting materials, jute sacks and small straw balls, on periparturient sow behaviour and piglet survival in both loose housing and in crates. 


\section{Materials and methods}

\subsection{Animals and treatments}

The experiment was carried out at the animal facilities of Swine Innovation Centre Sterksel, the Netherlands. It was analyzed as a $2 \times 2$ factorial arrangement, with the factors loose housing vs. crated housing during parturition and lactation and nesting material available before parturition, vs. no nesting material. Peri-parturient behaviour of sows of the Topigs-20 genetic line from eight successive farrowing batches was studied. Per batch, 12 crated sows and 4 loose housed sows farrowed. Within these batches, only parity 1-3 sows were studied. Observations on sows that received help during parturition, had a parturition duration of more than $7 \mathrm{~h}$ and savaged more than 2 piglets were excluded, leaving 68 sows in total for analysis, of which 44 were crated ( $n=26$ with and $n=18$ without nesting material) and 24 loose $(n=13$ with and $n=11$ without nesting material).

One week before expected farrowing, sows were placed in ProDromi ${ }^{\circledR}$ farrowing pens (Vereijken and Hooijer, Beek en Donk, Netherlands). These pens, developed by farmers, contained a piglet nest of $0.75 \times 1.50 \mathrm{~m}$ at the front of the pen with solid floor and floor heating (see Figure 1). The rest of the pen was fully slatted with plastic ironcast slats. A handful of wood shavings was used as bedding for the piglet nest. Sows were either confined in a $2.65 \mathrm{x}$ $1.80 \mathrm{~m}$ pen (Figure 1A) with farrowing crate, or loose in a different version of the ProDromi ${ }^{\circledR}$ farrowing pen $(2.65 \times 2.20 \mathrm{~m})$ with a movable fence along 2 sides to reduce the risk of crushing. All pens were equipped with a rope of $2.1 \mathrm{~m}$, hanging from a height of $1 \mathrm{~m}$ near the sows' feeding trough. Loose housed sows had free access to the piglet nest with their head. Per type of housing, half of the sows, balanced for parity, were provided with nesting material from one day before expected parturition, consisting of 2 straw balls $(12 \mathrm{~cm}, 60$ gr) and 2 jute sacks which were cut open $\left(1.2 \times 1.1 . \mathrm{m}, 220 \mathrm{gr} / \mathrm{m}^{2}\right)$ (MS Schippers, Bladel, the Netherlands). These 
materials were chosen because they can be manipulated by the sow (the jute sacks allowed for rooting and fluffing and the straw balls could be manipulated and teared apart by pulling out the straw) and are easy to use by farmers. When the straw balls or jute sacks were dirty or worn, new balls or sacks were provided.

Sows were fed twice a day, at $8.30 \mathrm{~h}$ and $15.30 \mathrm{~h}$, and received $2.8 \mathrm{~kg}$ of a commercial lactation diet per day before parturition, $2 \mathrm{~kg}$ on the day of parturition and then $0.5 \mathrm{~kg}$ extra per day, to a maximum of $7.5 \mathrm{~kg}$. All sows had ad libitum access to water. The room temperature was set at $18{ }^{\circ} \mathrm{C}$ at arrival and increased to $22{ }^{\circ} \mathrm{C}$ at the expected parturition date and the first 2 days postpartum. The lights were on from $7.30 \mathrm{~h}$ to $16.30 \mathrm{~h}$ and low intensity lighting was provided from $16.30 \mathrm{~h}$ to $7.30 \mathrm{~h}$ to enable video recordings.

\subsection{Data collection}

\subsubsection{Behavioural observations}

Video recordings were made from three days before the expected parturition date to two days after farrowing. Videos were analyzed using the Observer XT software (Noldus Information Technology B.V., The Netherlands). Video recordings were not available from one sow due to technical problems.

Before parturition (12-0 h). During the last $12 \mathrm{~h}$ before the first piglet was born, the behaviour of the sow was scored. Manipulation of fencing, floor and nesting material on the one hand, and body posture on the other hand, were scored using 5-min scan sampling in two mutually exclusive behaviour classes. The postures scored were standing, sitting, walking, lateral lying and ventral lying. The behaviours scored were sniffing, rooting, scratching, biting and other manipulation (if not clearly visible which type of manipulation) of floor, fence, rope, jute sack 
and straw ball, and other behaviour. Both postures and behaviours were expressed as a percentage of the total number of scans composing the observation period.

During parturition. During parturition, from birth of the first piglet until birth of the last piglet, the same postures and behaviours as before parturition were scored, but now continuously. In addition, the frequency of nose-nose contact with the piglets was recorded, and the initiator of this contact (sow, piglet, both or unknown). Furthermore, the total duration of parturition was scored (defined as the interval from birth of the first piglet until birth of the last piglet) and the number of posture changes was calculated. Also, the frequency of posture changes from a standing to a lying position was assessed and the number of crushing events, i.e. piglets getting stuck, irrespective of whether they survived or not. In addition, it was scored whether the sow stepped, sat, kneeled or lied down during crushing events.

After parturition $(0-24 h)$. From the birth of the last piglet up to $24 \mathrm{~h}$ later, manipulation behaviour and postures of the sow were scored using 5-min scan sampling as described for the period before parturition.

\subsubsection{Other parameters}

During parturition, the number of liveborn piglets, stillborn piglets and crushed piglets were counted using the video recordings. Within $24 \mathrm{~h}$ from parturition, all piglets (live born, stillborn, died) were weighed and non-vital piglets were euthanized (piglets below $750 \mathrm{~g}$ live weight or piglets with severe wounds). During the first $48 \mathrm{~h}$ after parturition, the number of piglets that died from crushing was assessed using the video recordings.

\subsection{Statistical analysis}

Statistical analyses were carried out in SAS (SAS, Version 9.2, SAS Institute Inc, Cary, USA). Residuals were checked for normality and variables were logarithmically (durations), square 
root (frequencies) or arcsine square root (proportion of scans composing the observation period) transformed when needed. Effects of housing (crated vs. loose), provision of nesting material (yes vs. no) and their interaction on behavioural variables were assessed using a mixed model that included the random effect of batch. Data are presented as means \pm SEM. Since only one significant interaction between housing and the provision of alternative nesting material was found, p-values for interactions are not shown in the tables.

\section{Results}

\subsection{Duration of parturition and piglet survival}

Performance around parturition is shown in Table 1. The duration of parturition $(3.3 \pm 0.1 \mathrm{~h})$ did not differ between treatments and neither did the number of piglets born $(14.0 \pm 0.4)$, average birth weight $(1.5 . \pm 0.1 \mathrm{~kg})$ and percentage of stillborn piglets $(3.2 \pm 0.7 \%)$. During parturition, loose housed sows tended to display less crushing and near-crushing events than crated sows $(0.4 \pm 0.2$ vs. $1.0 \pm 0.2, P=0.06)$, whereas the effect of housing on the number of pigs that died by crushing during parturition was non-significant $(0.1 \pm 0.1$ vs. $0.3 \pm 0.1, \mathrm{P}=$ 0.11).-In the first $48 \mathrm{~h}$ after parturition more piglets died by crushing in loose housed sows than in crated sows $(0.8 \pm 0.2$ vs. $0.3 \pm 0.1 ; \mathrm{P}=0.02)$. The total number of piglets that died by crushing up to $48 \mathrm{~h}$ after parturition did not differ between treatments $(0.7 \pm 0.1)$. Provision of alternative nesting material tended to reduce the total times lying down $(2.0 \pm 0.5$ vs. $3.8 \pm 0.8$, $\mathrm{P}<0.10)$ and the number of piglets that died by crushing during parturition $(0.1 \pm 0.05$ vs. 0.3 $\pm 0.1, P=0.06$ ). No other effects of provision of nesting material on performance data were found.

\subsection{Sow postures}


Table 2 shows the postures of the sow before, during and after parturition for the different treatments. In the $12 \mathrm{~h}$ before parturition, loose housed sows showed less sitting $(4.8 \pm 1.0 \%$ vs. $8.8 \pm 0.9 \%, \mathrm{P}<0.001)$, less ventral lying $(29.5 \pm 2.3 \%$ vs. $37.6 \pm 2.0 \%, \mathrm{P}=0.02)$ and more lateral lying $(32.5 \pm 3.6 \%$ vs. $22.5 \pm 2.2 \%, \mathrm{P}=0.02)$ than crated sows. Also during parturition, loose housed sows spent less time sitting $(2.0 \pm 0.6 \%$ vs. $6.1 \pm 0.8 \%, \mathrm{P}<0.001)$ and they showed fewer postural changes $(34.4 \pm 4.6$ vs. $49.7 \pm 4.6, \mathrm{P}=0.03)$. In the first $24 \mathrm{~h}$ after parturition, loose housed sows tended to show more lateral lying than crated sows $(82.3 \pm 1.3 \%$ vs. $77.8 \pm 1.5 \%, \mathrm{P}=0.09$ ).

The provision of nesting material increased the time spent lying during the $12 \mathrm{~h}$ before parturition $(63.3 \pm 2.6 \%$ vs. $57.2 \pm 2.9 \%, \mathrm{P}<0.05)$ and during parturition $(89.6 \pm 1.0 \%$ vs. 84.0 $\pm 2.7 \%, \mathrm{P}=0.03)$, and tended to reduce standing before parturition $(27.8 \pm 2.3 \%$ vs. $33.3 \pm$ $2.9 \%, \mathrm{P}=0.09)$ and reduced standing during parturition $(5.8 \pm 1.3 \%$ vs. $10.3 \pm 2.6 \%, \mathrm{P}=0.01)$. In the $24 \mathrm{~h}$ after parturition, postures were not affected by housing or nesting material, except that loose housed sows tended to show more lateral lying $(82.3 \pm 1.3$ vs. $77.8 \pm 1.5 \%, \mathrm{P}=$ $0.09)$.

\subsection{Manipulation of materials}

Table 3 shows the manipulation of material before, during and after parturition for the different treatments. Only one significant interaction between housing and the provision of nesting material was found for these parameters; in the $12 \mathrm{~h}$ before parturition, manipulation of the rope was reduced by the provision of nesting materials, but more strongly in loose housed sows (1.1 \pm 0.3 vs $8.0 \pm 1.8 \%)$ than in crated sows $(4.4 \pm 0.5$ vs. $8.7 \pm 1.4 \%), P=0.02$. In the $12 \mathrm{~h}$ before parturition, loose housed sows showed more activities directed to the floor (9.8 \pm 1.3 vs. $5.4 \pm$ $0.7 \%, \mathrm{P}<0.01)$, and tended to spent less time on manipulating the fence $(5.4 \pm 1.1$ vs. $7.3 \pm$ $0.8 \%, \mathrm{P}=0.07$, especially when nesting material was provided, $\mathrm{P}=0.09$ for interaction) than 
crated sows, although total time spent on manipulation of nesting material and pen did not differ between housing systems. During parturition loose housed sows showed less manipulation of the fence $(0.1 \pm 0.1 \%$ vs. $2.2 \pm 0.4 \%, \mathrm{P}<0.001)$ and rope $(0.6 \pm 0.4 \%$ vs $2.0 \pm 0.5 \%, \mathrm{P}=0.03)$ and tended to spent less time on manipulation of material $(6.1 \pm 1.4 \%$ vs $10.4 \pm 1.3 \%, \mathrm{P}=0.09)$. In the $24 \mathrm{~h}$ after parturition, manipulation of materials, fence and pen was not affected by housing.

The provision of nesting material reduced total time spent on manipulation of nesting material and pen $12-0 \mathrm{~h}$ before parturition $(23.6 \pm 1.5 \%$ vs. $26.3 \pm 1.8 \%, \mathrm{P}<0.05)$ and reduced manipulation of the floor $(4.9 \pm 0.6 \%$ vs. $9.8 \pm 1.1 \%, \mathrm{P}<0.001)$, fence $(5.0 \pm 0.7 \%$ vs. $8.9 \pm$ $1.0 \%, \mathrm{P}<0.01)$ and rope $(3.3 \pm 0.5 \%$ vs. $8.5 \pm 1.1 \%, \mathrm{P}<0.01)$. Also during parturition, sows with nesting material manipulated the rope less $(0.8 \pm 0.3 \%$ vs. $2.5 \pm 0.8 \%, \mathrm{P}=0.03)$ and tended to manipulate the fence less $(0.9 \pm 0.3 \%$ vs. $2.2 \pm 0.6 \%, \mathrm{P}=0.07)$. In the $24 \mathrm{~h}$ after parturition, sows with nesting material tended to manipulate the materials more $(0.7 \pm 0.1$ vs. $0.4 \pm 0.1), \mathrm{P}$ $=0.06)$.

\subsection{Nose-nose contact}

During parturition, the frequency of nose-nose contacts between sows and piglets was significantly higher in loose housed sows than in crated sows $(56.3 \pm 7.9$ vs. $18.5 \pm 3.2$, P < 0.001; Table 4). The percentage of nose contacts initiated by the sow did not differ between treatments, but in loose housing the percentage of contacts initiated by the piglets was higher than in crated sows $(63.4 \pm 4.4$ vs. $53.0 \pm 5.6 \%, \mathrm{P}<0.05)$ and fewer contacts were initiated by both $(14.3 \pm 1.9$ vs. $27.3 \pm 3.8 \%, \mathrm{P}=0.03)$.

\section{Discussion}


Both housing and the provision of alternative nesting material influenced periparturient behaviour of sows and piglet survival. Generally, effects of housing and of nesting material were additive rather than interactive, suggesting that these two factors relatively independently affected the periparturient processes studied and therefore these factors will be discussed separately.

\section{Loose housing vs. confinement in crates}

The total time spent on manipulation behaviours (manipulating nesting material, floor and fences) during the $12 \mathrm{~h}$ before parturition did not differ between loose housed and crated sows. The loose housed sows in our study spent, however, more time on manipulating the floor, and directed less attention to the rope and the fence, especially when other materials were provided. In contrast with the present results, others found increased nestbuilding activities in loose house sows (Jarvis et al., 2002; Yun et al., 2014), except during the last hours before parturition (Andersen et al., 2014) albeit definitions of nestbuilding activities vary between studies as do designs of loose housing.

Loose housing in our study did reduce the time spent sitting and ventral lying, and increased lateral lying in the $12 \mathrm{~h}$ preceding parturition. A decreased activity in loose housing as opposed to crates is in line with the study by Hansen and Curtis (1980) who found less standing in the $48 \mathrm{~h}$ before the onset of parturition in penned sows. In contrast, others reported that sows loose housed in pens showed more standing and less lateral lying compared to crated sows in the 24 h-period before farrowing (Jarvis et al., 2002). The penned sows in their study showed, however, a greater reduction in nest building activities in the last $3.5 \mathrm{~h}$ before farrowing than sows housed in crates, suggesting an earlier cessation of nest building when loose housed (Jarvis et al., 2004). The latter may reflect positive feedback from the built nest, i.e. a more or 
less satisfying result of the nestbuilding activities (Wischner et al., 2009). Prepartum nestbuilding activities usually peak between 12 to $6 \mathrm{~h}$ before farrowing (see Wischner et al., 2009 for review), and a large amount of nesting behaviour shortly before and during parturition may reflect stress and negatively affect post-partum piglet performance (Illmann et al., 2015). It could be speculated that the lower prepartum activity in the loose-housed sows in the current study reflects an earlier cessation of nest building behaviour. Alternatively, the increased lateral lying in our loose housed sows may have reflected better lying opportunities due to increased space allowance.

In line with other studies, the time spent sitting both before (Cronin et al., 1993) and during (Jarvis et al., 2004) parturition was higher in crated sows (Gu et al., 2011) and tended to be higher in the $24 \mathrm{~h}$ after farrowing. It has been stated that sitting reflects a conflict between the motivation to build a nest and the inability to do so because of environmental constriction (Jarvis et al., 1999). During parturition, the crated sows also showed more postural changes than loose housed sows, which is in line with results of other studies (Jarvis et al., 1997; 2004). In addition, crated sows spent more time on manipulating the fence and the rope during farrowing. This apparent restlessness could be a carryover effect from the pre-parturient period as the thwarting of nestbuilding activities in crates has been shown to result in increased stress (Jarvis et al., 1997; 2002). Sows that are restless shortly before farrowing have been described to be less protective in their post-farrowing maternal behaviour and tended to crush more piglets (e.g. Andersen et al., 2005). In the current study, the behavioural differences between sows in crates vs. loose housing tended to be reflected in the number of (near)crushing events; crated pigs numerically crushed more piglets $(\mathrm{P}=0.11)$. Crated sows crushed fewer piglets during the first $48 \mathrm{~h}$ after parturition, even though they tended to show less lateral lying on the first day after parturition, with no significant effect of housing on total number of piglets crushed during parturition up till 2 days thereafter. 
Loose housed sows made more nose contact with their piglets and the piglets made more contact with their mother during parturition. This is in accordance with the findings of Jarvis et al., (2004), who stated that the provision of space encourages piglet-sow interactions, with piglets being more around the head of the sows particularly during early parturition. Others also stated that in loose housed sows, nose-to-nose contacts are common during parturition and early stages of lactation (Jarvis et al., 2004; Whatson and Bertram, 1982/83) and thought to be important for (re-)establishing the identity of the piglet that the sow is nursing (Whatson and Bertram, 1982/83).

\section{Provision of alternative nesting materials}

Provision of an abundance of nesting materials has been shown to have major neuroendocrine effects on the sow, such as higher prolactin and oxytocin concentrations until day 7 post partum (Yun et al., 2013). It is unlikely that the provision of jute sacks and straw balls provided in the present study is sufficient to perform appropriate nest building behaviour and create a completely satisfactory nest. Yet, we found several behavioural effects of the provision of these materials that can be interpreted as favourable.

In the $12 \mathrm{~h}$ before parturition, the attention of the sows provided with jute sacks and straw balls seemed to be attracted to these materials, as these sows spent significantly more time on manipulating nesting material and less time manipulating the floor, rope and fence than the sows without these nesting materials. The jute sack was manipulated much longer than the straw balls, possibly because it better resembles the nesting substrates that can be found in the natural environment. Total time spent on manipulative, nestbuilding behaviours directed to the provided materials (straw, jute sack and rope), and nestbuilding-like behaviours directed to the fence and floor was was lower for sows provided with the nesting materials. Others found more profound effects of the provision of nesting materials on nestbuilding activities (Burne et al., 
2000). Again, definitions of nestbuilding activity vary between studies either in- or excluding manipulation of pen fixtures, which could reflect sham nestbuilding activities. It should be noted that sows without the nesting materials in this study directed a major part of their manipulation behaviour to the floor and fence, and it can be questioned to what extend this behaviour does reflect rewarding nest building behaviour.

Sows provided with jute sacks and straw balls spent more time lying and tended to spend less time standing in the $12 \mathrm{~h}$ before parturition which may suggest that these sows settled down in a resting position earlier. It has been suggested that nestbuilding is completed sooner if the materials provided are more suitable (Wischner et al., 2009). It could well be that the jute sacks provided some 'udder comfort', which has been proposed as an important stimulus for cessation of nestbuilding (Baxter, 1983).

During parturition, sows that had access to nesting material also showed more lying behaviour and less standing, and tended to stand up less often. Moreover, they showed less manipulation of the rope, particularly when loose housed, and tended to show less manipulation of the fence. This inactivity during farrowing is an important aspect of maternal care in pigs favouring piglet survival (Jarvis et al., 1997). These behavioural changes in sows provided with alternative nest material indeed were associated with a tendency for a lower number of piglets crushed during parturition.

Several studies suggest that suboptimal conditions around farrowing may lead to a prolonged parturition, which, in turn, increases the risk of mortality during birth. In line with this, some studies report shorter durations of farrowing and lower still birth rates in sows provided with nesting materials (Cronin et al. 1993, parturition duration 2.7 vs. $3.3 \mathrm{~h}$ in younger sows) or in sows kept in pens as compared with crates (Gu et al. 2011, parturition duration 3.6 vs. $4.9 \mathrm{~h}$; 
still birth rate 4.1 vs. $10.5 \%)$. Duration of parturition $(3.3 \mathrm{~h})$ or still birth rate $(3.2 \%)$ in this study, with higher litter sizes than the two studies mentioned above, were, however, not affected by housing type or provision of nesting material.

In conclusion, both loose housing and the provision of alternative nesting materials affected the behaviour of the sow before parturition and resulted in less activity during parturition, with some tendencies for beneficial effects on (near-)crushing of piglets during this period. In conclusion, both loose housing and the provision of alternative nesting materials, likely particularly the jute sacks, have a beneficial effect on periparturient sow behaviour.

\section{Acknowledgements}

The study was funded by the Dutch Ministry of Economic Affairs and the Dutch Productboard for Livestock and Meat. 


\section{References}

Andersen, I.L., Berg, S., Boe, K.E., 2005. Crushing of piglets by the mother sow (Sus scrofa) - purely accidental or a poor mother? Appl. Anim. Behav. Sci. 93, 229-243.

Andersen, I.L., Vasdal, G., Pedersen, L.J., 2014. Nest building and posture changes and activity budget of gilts housed in pens and in crates. Appl. Anim. Behav. Sci. 159, 29-33.

Algers, B., Uvnäs-Moberg, K., 2007. Maternal behavior in pigs. Horm. Behav. 52, 78-85.

Baxter, M.R. 1983. Ethology in environmental design for animal production. Appl. Anim. Ethol. 9, 207-220.

Burne, T.H.J., Murfitt, P.J.E., Gilbert, C.L., 2000. Deprivation of straw bedding alters PGF2a -induced nesting behaviour in female pigs. Appl. Anim. Behav. Sci. 69: 215-225.

Cronin, G.M., van Amerongen, G., 1991. The effect of modifying the farrowing environment on sow behaviour and survival and growth of piglets. Appl. Anim. Behav. Sci. 30, 287-298.

Cronin, G.M., Schirmer, B.N., McCallum, T.H., Smith, J.A., Butler, K.L., 1993. The effects of providing sawdust to pre-parturient sows in farrowing crates on sow behaviour, the duration of parturition and the occurrence of intra-partum stillborn piglets. Appl. Anim. Behav. Sci. $36,301-315$.

Gu, Z., Yajun, G., Baozhong, L., Zhengze, Z., Zuohua, L., Chaoyuan, W., Baoming, L., 2011. Impacts of a freedom farrowing pen design on sow behaviours and performance. Prev. Vet. Med. 102: 296-303.

Gustafsson, M., Jensen, P., de Jonge, F.H., Illman, G., Špinka, M., 1999. Maternal behaviour of domestic sows and crosses between domestic sows and wild boar. Appl. Anim. Behav. Sci. $65,29-42$.

Hansen, K.E., Curtis, S.E., 1980. Prepartal activity of sows in stall or pen. J. Anim. Sci. 51, $456-460$ 
Herskin, M.S., Jensen, K.H., Thodberg, K., 1998. Influence of environmental stimuli on maternal behaviour related to bonding, reactivity and crushing of piglets in domestic sows. Appl. Anim.Behav. Sci. 58, 241-254.

IIlmann, G., Chaloupková, H., Neuhauserová, K., 2015. Effect of pre- and post-partum sow activity on maternal behaviour and piglet weight gain $24 \mathrm{~h}$ after birth. Appl. Anim.Behav. Sci. $163,80-88$.

Jarvis, S., Lawrence, A.B., McLean, K.A., Deans, L.A., Chirnside, J., Calvert, S.K.,. 1997. The effect of environment on behavioural activity, ACTH, beta-endorphin and cortisol in prefarrowing gilts. Anim. Sci. 65, 465-472.

Jarvis, S., McLean, K.A., Calvert, S.K., Deans, L.A., Chirnside, J., Lawrence, A.B. 1999. The responsiveness of sows to their piglets in relation to the length of parturition and the involvement of endogenous opioids. Appl. Anim.Behav. Sci. 63: 195-207.

Jarvis, S., Calvert, S.K., Stevenson, J., Leeuwen, N. van, Lawrence, A.B., 2002. Pituitaryadrenal activation in pre-parturient pigs (Sus scrofa) is associated with behavioural restriction due to lack of space rather than nesting substrate. Anim. Welf, 11: 371-384.

Jarvis, S., Reed, B.T., Lawrence, A.B., Calvert, S.K., Stevenson, J., 2004. Peri-natal environmental effects on maternal behaviour, pituitary and adrenal activation, and the progress of parturition in the primiparous sow. Anim. Welf. 13, 171-181.

Lawrence, A.B., Petherick, J.C., McLean, K.A., Deans, L.A., Chirnside, J., Vaughan, A., Clutton, E., Terlouw, E.M.C., 1994. The effect of environment on behaviour, plasma cortisol and prolactin in parturient sows. Appl. Anim.Behav. Sci. 39, 313-330.

Oliviero, C., Heinonen, M., Valros, A., Hälli, O., O.A.T. Peltoniemi., 2008. Effect of the environment on the physiology of the sow during late pregnancy, farrowing and early lactation. Anim. Reprod. Sci. 105, 365-377. 
Thodberg , K., Jensen, K.H., Herskin, M.S., Jørgensen, E., 1999. Influence of environmental stimuli on nest building and farrowing behaviour in domestic sows. Appl. Anim. Behav. Sci. $63,131-144$.

Tuyttens, F.A.M., 2005. The importance of straw for pig and cattle welfare: A review. Appl. Anim. Behav. Sci. 92: 261-282.

Westin, R., Hultgren, J., Algers, B., 2015. Strategic use of straw increases nest building in loose housed sows. Appl. Anim. Behav. Sci. 166, 63-70.

Whatson, T.S., Bertram, J.M., 1982/83. Some observations on mother-infant interactions in the pig (Sus scrofa). Appl. Anim. Ethol. 9, 253-261.

Wischner, D., Kemper, N., Krieter, J., 2009. Nest-building behaviour in sows and consequences for pig husbandry. Livest. Sci. 124, 1-8.

Yun, J., Swan, K.-M., Vienola, K., Farmer, C., Oliviero, C., Peltoniemi, O., Valros, A., 2013. Nestbuilding in sows: Effects of farrowing housing on hormonal modulation of maternal characteristics. Appl. Anim. Behav. Sci. 148, 77-84.

Yun, J., Swan, K.-M., Oliviero, C., Peltoniemi, O., Valros, A., 2014. Pre-partum nestbuilding has an impact on postpartum nursing performance and maternal behaviour in early lactating sows. Appl. Anim. Behav. Sci. 160, 31-37.

Yun, J., Valros, A., 2015. Benefits of prepartum nest-building behaviour on parturition and lactation in sows - a review. Asian Australas. J. Anim. Sci. 28(11), 1519-1524 

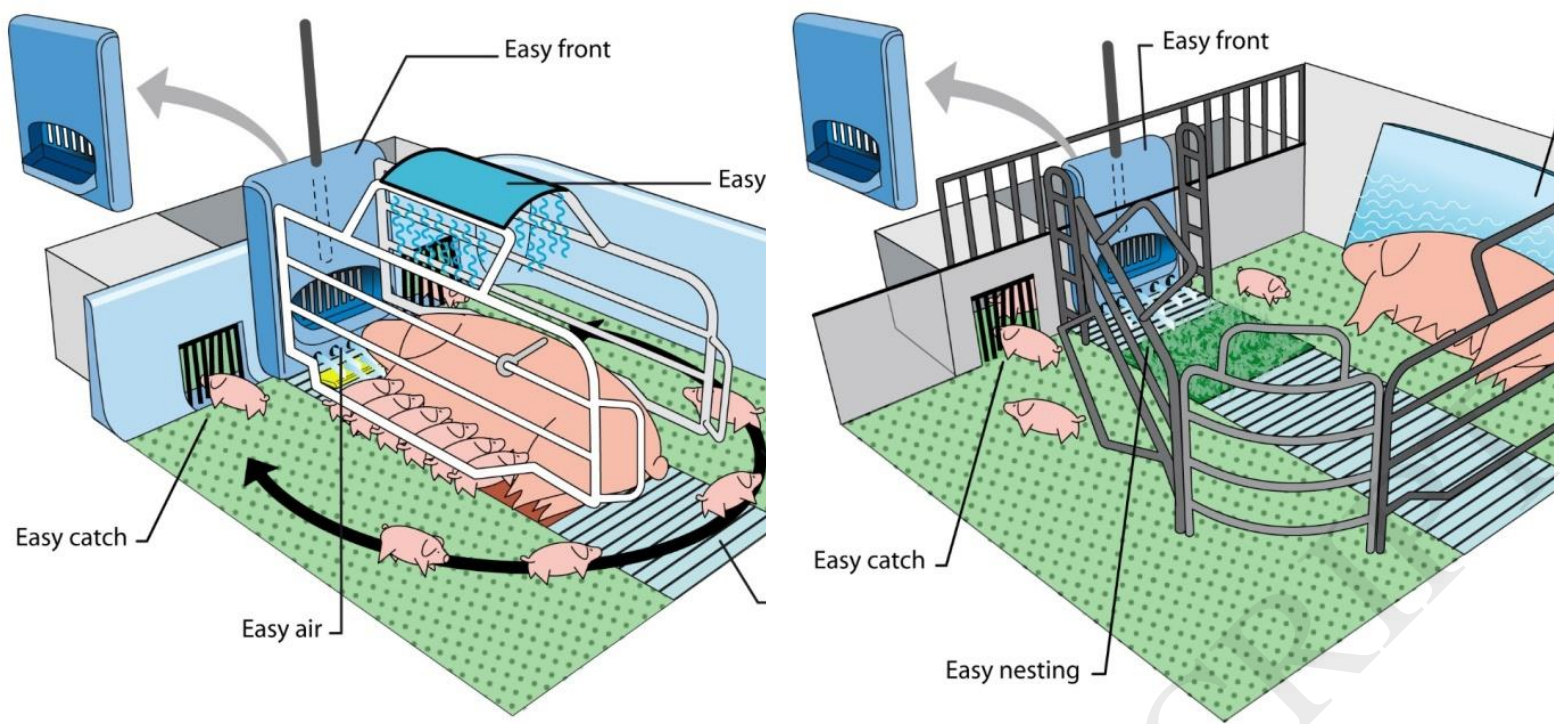

Figure 1

Schematic representation of the ProDromi ${ }^{\circledR}$ farrowing pen with crate (left panel) and the loose housing version (right panel). In this experiment, the left fence in the loose housing pen was placed such that the sow had access to the piglet nest with her snout. 


\begin{tabular}{|c|c|c|c|c|c|c|}
\hline & & ted & & ose & & $\operatorname{lue}^{1}$ \\
\hline Nesting material & Yes & No & Yes & No & Housing & Material \\
\hline $\mathrm{N}$ & 26 & 18 & 13 & 11 & & \\
\hline Duration of parturition (h) & $3.51 \pm 0.21$ & $3.29 \pm 0.30$ & $3.32 \pm 0.31$ & $2.89 \pm 0.41$ & 0.34 & 0.30 \\
\hline \multicolumn{7}{|l|}{ Piglets born } \\
\hline Total & $14.7 \pm 0.6$ & $13.3 \pm 0.6$ & $13.7 \pm 1.0$ & $13.7 \pm 0.9$ & 0.39 & 0.64 \\
\hline Average birth weight total born $(\mathrm{kg})$ & $1.45 \pm 0.07$ & $1.37 \pm 0.06$ & $1.45 \pm 0.06$ & $1.36 \pm 0.05$ & 0.96 & 0.27 \\
\hline Stillborn (\%) & $2.8 \pm 1.3$ & $2.4 \pm 1.0$ & $4.2 \pm 1.5$ & $4.5 \pm 2.0$ & 0.24 & 0.99 \\
\hline $\begin{array}{l}\text { Euthanized low birth weight }(<750 \\
\text { g) }\end{array}$ & $0.5 \pm 0.2$ & $0.3 \pm 0.1$ & $0.2 \pm 0.1$ & $0.8 \pm 0.5$ & 0.96 & 0.31 \\
\hline Euthanized other reasons & $0.3 \pm 0.2$ & $0.1 \pm 0.0$ & $0.3 \pm 0.0$ & $0.6 \pm 0.3$ & 0.28 & 0.41 \\
\hline \multicolumn{7}{|l|}{ Piglets dead by crushing } \\
\hline During parturition & $0.2 \pm 0.1$ & $0.4 \pm 0.1$ & 0 & $0.2 \pm 0.1$ & 0.11 & 0.06 \\
\hline $0-48 \mathrm{~h}$ after parturition & $0.3 \pm 0.1$ & $0.4 \pm 0.2$ & $0.9 \pm 0.3$ & $0.7 \pm 0.2$ & 0.02 & 0.74 \\
\hline Total up to $48 \mathrm{~h}$ after parturition & $0.4 \pm 0.2$ & $0.8 \pm 0.3$ & $0.9 \pm 0.3$ & $0.9 \pm 0.3$ & 0.14 & 0.26 \\
\hline \multicolumn{7}{|l|}{ (Near-)crushing events during parturition } \\
\hline Total times lying down ${ }^{2}$ & $2.1 \pm 0.6$ & $4.5 \pm 1.0$ & $1.9 \pm 0.9$ & $2.3 \pm 0.8$ & 0.31 & $<0.10$ \\
\hline Total (near-)crushing events & $0.9 \pm 0.3$ & $1.2 \pm 0.3$ & $0.3 \pm 0.2$ & $0.6 \pm 0.4$ & 0.06 & 0.29 \\
\hline Due to lying down ${ }^{2}$ & $0.4 \pm 0.2$ & $0.5 \pm 0.2$ & $0.1 \pm 0.1$ & $0.4 \pm 0.4$ & 0.19 & 0.30 \\
\hline Due to other postural changes & $0.5 \pm 0.2$ & $0.6 \pm 0.2$ & $0.2 \pm 0.2$ & $0.1 \pm 0.1$ & 0.09 & 0.76 \\
\hline
\end{tabular}




\begin{tabular}{|c|c|c|c|c|c|c|}
\hline & & ted & & & & alue $^{1}$ \\
\hline Nesting material & Yes & No & Yes & No & Housing & Material \\
\hline $\mathrm{N}$ & 26 & 18 & 13 & 10 & & \\
\hline \multicolumn{7}{|l|}{ 12-0h before parturition } \\
\hline Standing & $27.9 \pm 2.8$ & $30.7 \pm 4.0$ & $27.7 \pm 4.0$ & $37.9 \pm 3.7$ & 0.39 & 0.09 \\
\hline Sitting & $8.4 \pm 1.3$ & $9.3 \pm 1.1$ & $4.7 \pm 1.3$ & $5.1 \pm 1.6$ & $<0.001$ & 0.65 \\
\hline Total lying & $61.8 \pm 3.4$ & $57.6 \pm 3.8$ & $66.2 \pm 3.8$ & $55.2 \pm 4.8$ & 0.65 & $<0.05$ \\
\hline Lying ventrally & $38.4 \pm 2.6$ & $36.5 \pm 3.4$ & $33.5 \pm 3.4$ & $24.6 \pm 2.2$ & 0.02 & $<0.10$ \\
\hline Lying laterally & $23.4 \pm 3.1$ & $21.2 \pm 3.0$ & $34.2 \pm 4.5$ & $30.5 \pm 5.9$ & 0.02 & 0.37 \\
\hline \multicolumn{7}{|l|}{ Parturition } \\
\hline Postural changes & $48.2 \pm 6.5$ & $51.6 \pm 6.5$ & $36.9 \pm 6.6$ & $31.1 \pm 6.6$ & 0.03 & 0.87 \\
\hline Standing & $6.2 \pm 1.8$ & $7.3 \pm 2.0$ & $5.1 \pm 1.9$ & $15.3 \pm 5.9$ & 0.48 & 0.01 \\
\hline Sitting & $5.3 \pm 0.8$ & $7.3 \pm 1.7$ & $2.4 \pm 0.9$ & $1.5 \pm 0.6$ & $<0.001$ & 0.88 \\
\hline Total lying & $88.2 \pm 2.0$ & $84.6 \pm 2.7$ & $92.2 \pm 2.6$ & $83.1 \pm 5.7$ & 0.22 & 0.03 \\
\hline Lying ventrally & $15.7 \pm 2.3$ & $8.9 \pm 1.6$ & $11.6 \pm 3.0$ & $6.8 \pm 2.2$ & 0.14 & 0.02 \\
\hline Lying laterally & $72.6 \pm 2.9$ & $75.8 \pm 3.1$ & $80.6 \pm 4.5$ & $76.2 \pm 5.8$ & 0.13 & 0.96 \\
\hline \multicolumn{7}{|l|}{$0-24 \mathrm{~h}$ after parturition } \\
\hline Standing & $4.3 \pm 0.6$ & $4.1 \pm 0.7$ & $3.4 \pm 0.6$ & $5.8 \pm 0.9$ & 0.73 & 0.11 \\
\hline Sitting & $1.2 \pm 0.2$ & $1.2 \pm 0.3$ & $0.8 \pm 0.2$ & $0.6 \pm 0.2$ & 0.09 & 0.90 \\
\hline Total lying & $94.3 \pm 0.7$ & $94.2 \pm 0.8$ & $95.7 \pm 0.6$ & $93.4 \pm 1.0$ & 0.57 & 0.11 \\
\hline Lying ventrally & $16.5 \pm 2.0$ & $16.2 \pm 2.4$ & $11.7 \pm 1.9$ & $13.4 \pm 1.9$ & 0.19 & 0.65 \\
\hline Lying laterally & $77.7 \pm 2.2$ & $78.0 \pm 2.2$ & $84.0 \pm 1.6$ & $80.0 \pm 2.1$ & 0.09 & 0.36 \\
\hline
\end{tabular}




\begin{tabular}{|c|c|c|c|c|c|c|}
\hline \multicolumn{7}{|c|}{$\begin{array}{l}\text { Table } 3 \\
\text { Manipulation of material ( } \% \text { of time, raw mean } \pm \text { SEM) before, during and after parturition } \\
\text { of parity } 1-3 \text { sows in different farrowing housing (crated vs. loose) and provided with nesting } \\
\text { material or not. }\end{array}$} \\
\hline & \multicolumn{2}{|c|}{ Crated } & \multicolumn{2}{|c|}{ Loose } & \multicolumn{2}{|c|}{$\mathrm{p}$-value } \\
\hline Nesting material & Yes & No & Yes & No & Housing & Material \\
\hline Number of sows & 26 & 18 & 13 & 10 & 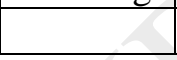 & 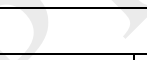 \\
\hline \multicolumn{7}{|c|}{ 12-Oh before parturition } \\
\hline Total $^{1}$ & $23.7 \pm 2.0$ & $25.2 \pm 2.0$ & $23.4 \pm 2.3$ & $30.8 \pm 2.5$ & 0.26 & $<0.05$ \\
\hline Floor & $4.0 \pm 0.8$ & $7.5 \pm 1.0$ & $6.6 \pm 0.8$ & $13.8 \pm 2.6$ & $<0.01$ & $<0.001$ \\
\hline Fence $^{2}$ & $6.1 \pm 1.0$ & $8.9 \pm 1.1$ & $2.7 \pm 0.5$ & $9.0 \pm 1.9$ & 0.07 & $<0.001$ \\
\hline Materials & $13.6 \pm 1.3$ & $8.7 \pm 1.4$ & $14.1 \pm 2.0$ & $8.0 \pm 1.8$ & 0.98 & $<0.01$ \\
\hline Straw & $1.7 \pm 0.7$ & - & $1.1 \pm 0.4$ & - & 0.62 & - \\
\hline Sack & $4.4 \pm 0.9$ & - & $6.7 \pm 1.6$ & - & 0.44 & - \\
\hline Rope $^{3}$ & $4.4 \pm 0.5^{\mathrm{a}}$ & $8.7 \pm 1.4^{\mathrm{b}}$ & $1.1 \pm 0.3^{\mathrm{c}}$ & $8.0 \pm 1.8^{\mathrm{ab}}$ & 0.03 & $<0.001$ \\
\hline \multicolumn{7}{|l|}{ During parturition } \\
\hline Total $^{1}$ & $10.0 \pm 1.7$ & $10.9 \pm 2.2$ & $5.9 \pm 2.3$ & $7.3 \pm 1.9$ & 0.10 & 0.53 \\
\hline Floor & $4.5 \pm 1.4$ & $4.6 \pm 1.5$ & $3.8 \pm 1.7$ & $5.6 \pm 1.5$ & 0.91 & 0.21 \\
\hline Fence & $1.4 \pm 0.3$ & $3.2 \pm 0.8$ & $0.06 \pm 0.03$ & $0.20 \pm 0.11$ & $<0.001$ & 0.07 \\
\hline Material & $4.1 \pm 0.8$ & $3.1 \pm 1.1$ & $1.9 \pm 0.9$ & $1.5 \pm 0.9$ & 0.09 & 0.17 \\
\hline Straw & $0.6 \pm 0.3$ & - & $0.02 \pm 0.02$ & - & 0.14 & - \\
\hline Sack & $2.3 \pm 0.5$ & - & $1.9 \pm 0.9$ & - & 0.95 & - \\
\hline Rope & $1.2 \pm 0.4$ & $3.1 \pm 1.1$ & $0.003 \pm 0.003$ & $1.5 \pm 0.9$ & 0.03 & 0.03 \\
\hline \multicolumn{7}{|c|}{$0-24 \mathrm{~h}$ after parturition } \\
\hline Total $^{1}$ & $4.9 \pm 1.2$ & $5.2 \pm 1.3$ & $8.2 \pm 2.0$ & $12.2 \pm 2.9$ & 0.61 & 0.65 \\
\hline Material & $0.7 \pm 0.2$ & $0.5 \pm 0.2$ & $0.6 \pm 0.2$ & $0.2 \pm 0.1$ & 0.31 & 0.06 \\
\hline \multicolumn{7}{|c|}{$\begin{array}{l}{ }^{1} \text { Sum of all sniffing, rooting, manipulating, scratching and biting the floor, fence, straw, sack } \\
\text { and rope; }{ }^{2} \text { Interaction } \mathrm{P}=0.02 ;{ }^{3} \text { Interaction } \mathrm{P}=0.09 \text {; all other Housing } \mathrm{x} \text { Material } \\
\text { interactions } \mathrm{P}>0.10 \text {. }\end{array}$} \\
\hline
\end{tabular}




\begin{tabular}{|c|c|c|c|c|c|c|}
\hline \multicolumn{7}{|l|}{$\begin{array}{l}\text { Table } 4 \\
\text { Nose-nose contacts (mean } \\
\text { different farrowing housing }\end{array}$} \\
\hline \multirow{2}{*}{ Alternative material } & \multicolumn{2}{|c|}{ Crated } & \multicolumn{2}{|c|}{ Loose } & \multicolumn{2}{|c|}{ p-value ${ }^{1}$} \\
\hline & Yes & No & Yes & No & Housing & Material \\
\hline$n$ & 23 & 17 & 13 & 10 & & \\
\hline Total number of contacts & $21.6 \pm 4.9$ & $14.4 \pm 3.5$ & $56.0 \pm 11.1$ & $56.7 \pm 11.7$ & $<0.001$ & 0.83 \\
\hline Initiation by sow ${ }^{2}$ & $15.9 \pm 4.0$ & $22.4 \pm 5.1$ & $16.1 \pm 3.3$ & $22.8 \pm 3.7$ & 0.47 & 0.16 \\
\hline Initiation by piglets ${ }^{2}$ & $56.6 \pm 7.6$ & $48.6 \pm 8.0$ & $67.5 \pm 5.3$ & $64.4 \pm 4.7$ & $<0.05$ & 0.62 \\
\hline Initiation by both ${ }^{2}$ & $26.2 \pm 5.7$ & $28.9 \pm 5.6$ & $16.2 \pm 3.2$ & $12.8 \pm 1.7$ & 0.03 & 0.67 \\
\hline \multicolumn{7}{|c|}{${ }^{1} \mathrm{P}>0.10$ for all Housing $\mathrm{x}$ Material interactions $;{ }^{2}$ Percentage of total number of contacts; initiation } \\
\hline
\end{tabular}

